\title{
Assessing the effectiveness of public awareness- raising initiatives for the Hainan gibbon Nomascus hainanus
}

\author{
Junfei Qian, Morena Mills, Heidi Ma and Samuel T. Turvey
}

\begin{abstract}
Many protected areas conduct awareness-raising activities to increase local knowledge and support conservation programmes, but the effectiveness of such activities is rarely assessed. Public awareness-raising has been carried out since the early 2000 s around Bawangling National Nature Reserve, Hainan, China, to improve conservation knowledge about the Critically Endangered Hainan gibbon Nomascus hainanus, one of the rarest mammals. We conducted 207 interviews in 25 villages around Bawangling National Nature Reserve to evaluate the outcome of previous conservation education, through comparison of variation in local respondent knowledge and attitudes, and specific enquiries about sources of knowledge acquisition. Likelihood of accurate responses to most of our questions regarding the species was positively correlated with local exposure to gibbon-themed billboards and murals, and respondents exhibited greater knowledge about several key conservation indices for gibbons compared to their knowledge about sympatrically occurring rhesus macaques Macaca mulatta. Many respondents specifically reported they knew about local existence, population size, conservation status, and threats to gibbons from past awareness-raising activities, with village education sessions and billboards widely identified as key sources of information. However, other known awareness-raising approaches have had little detectable effect on shaping local conservation awareness. Although educational activities have improved awareness about gibbons and their conservation requirements in relative terms, overall levels of knowledge remain low in many important areas and ongoing improvement of local awareness is still needed, in particular around poorly-understood topics such as gibbon conservation status, rarity and threats, and for socio-demographic groups possessing less conservation knowledge.
\end{abstract}

JUnfei Qian ${ }^{*}$ and Morena Mills Imperial College London, Silwood Park Campus, Ascot, UK

HeIDI MA* School of Biological Sciences, Royal Holloway University of London, Egham, UK

Samuel T. Turvey (Corresponding author, (1) orcid.org/0000-0002-3717-4800) Institute of Zoology, Zoological Society of London, Regent's Park, London, NW1 4RY, UK. E-mail samuel.turvey@ioz.ac.uk

${ }^{*}$ Also at: Institute of Zoology, Zoological Society of London, London, UK

Received 13 January 2020. Revision requested 16 March 2020

Accepted 17 June 2020. First published online 14 April 2021.
Keywords Awareness-raising, China, conservation effectiveness, environmental education, evidence-based conservation, Hainan gibbon, interview survey, Nomascus hainanus

Supplementary material for this article is available at doi.org/10.1017/So030605320000599

\section{Introduction}

- stablishment of protected areas is a primary strategy to 1 counteract ongoing declines in global biodiversity, and $>161,000$ protected areas now exist, covering $14.7 \%$ of the Earth's terrestrial surface and $10 \%$ of its territorial waters (UNEP-WCMC \& IUCN, 2016). However, large local human populations often live inside or adjacent to protected areas. Local inhabitants can negatively affect conservation effectiveness of protected areas by exploiting natural resources within them for food, medicines, firewood and other raw materials (Dzerefos \& Witkowski, 2001; Ormsby \& Kaplin, 2005; Larson et al., 2016). Conversely, Indigenous knowledge and cultural practices in rural communities living in conservation-priority landscapes can support conservation activities (Berkes et al., 2000; Fernández-Llamazares \& Cabeza, 2018). Support and involvement of local communities is therefore vital for successful management of protected areas, and has encouraged development of many community-based conservation strategies (Madden, 2004).

It is impossible to establish community support or involvement in protected area conservation without local awareness about a protected area's existence (Ormsby \& Kaplin, 2005), or about the nature and goals of conservation activities (Booth et al., 2009). Many site-based conservation programmes have therefore initiated education and outreach projects to raise local conservation awareness (e.g. Igota \& Suzuki, 2008; van der Ploeg et al., 2011), and public awareness-raising initiatives play an increasingly important role in conservation (Monroe, 2003). However, information on the effectiveness of awareness-raising activities is often lacking, making it impossible to determine whether awareness has actually improved amongst relevant resource users or other stakeholders, or which educational approaches are most effective or locally appropriate (Bajracharya et al., 2005; Ferraro \& Pattanayak, 2006). For example, there is currently only limited evidence to assess the effectiveness of educating local communities about primates and 
sustainable use, and no evidence about the effectiveness of activities such as installing billboards to raise conservation awareness about primates (Wild et al., 2005; Junker et al., 2019). The outcome of awareness-raising initiatives therefore needs to be documented, assessed, and substantiated using scientific evidence to support future approach improvements (Sutherland et al., 2004). This is particularly important for biodiversity-rich countries, where financial resources for conservation are often limited (Sodhi et al., 2010).

The Hainan gibbon Nomascus hainanus, a primate endemic to Hainan Island, China's southernmost province, is the rarest ape and one of the rarest mammals. Its population declined as a result of habitat loss and hunting for food and traditional medicine, and only one remnant population of c. 27 individuals survives (Chan et al., 2005; Fellowes et al., 2008; Turvey et al., 2015; Deng et al., 2017). This Critically Endangered species is now restricted to a single protected area, Bawangling National Nature Reserve, established in 1980 specifically to protect gibbons (Chan et al., 2005; Turvey et al., 2015). Numerous villages lie close to the Reserve boundary, and local people (primarily Li and Miao ethnic groups) utilize resources collected from within the protected area (Chan et al., 2005; Fauna \& Flora International China Programme, 2005; Turvey et al., 2015). As part of a wider conservation programme, public awareness-raising activities have been conducted since the early 2000 s to promote local awareness of the Reserve and gibbon conservation and to provide environmental education (Plate 1; Supplementary Table 1). The Reserve management office has cooperated with local and international NGOs to organize education sessions within villages and at local schools to provide information about gibbon status and conservation legislation, to construct permanent billboards displaying gibbon-related information and images, and to paint murals and distribute posters and other materials showing gibbons and other local biodiversity (Chan et al., 2005; Fauna \& Flora International China Programme, 2005; Fellowes et al., 2008; Turvey et al., 2015). Ongoing educational activities have been identified as a priority action to support Hainan gibbon conservation (Turvey et al., 2015).

There has been little assessment of the overall impact or effectiveness of awareness-raising for enhancing local understanding about the Hainan gibbon or the Reserve, or the relative effectiveness of different activities in promoting conservation awareness (Fellowes et al., 2008). A community survey in 2015, in which 107 respondents in 10 villages around Bawangling were interviewed as part of a wider project investigating Indigenous knowledge about Hainan's biodiversity, suggested local awareness of gibbons was relatively low: only $74 \%$ of respondents at Bawangling could identify a gibbon photograph and only $46 \%$ were aware of the status of gibbons locally (Turvey et al., 2017). We therefore conducted a separate large-scale interview survey in villages around Bawangling, aiming specifically to assess the effectiveness of past conservation awareness-raising, by determining patterns of local awareness about gibbons and the Reserve and identifying factors associated with variation in awareness (including socio-demographic factors and the relative effect of different awareness-raising activities). The results of this study are intended to assist Bawangling $\mathrm{Na}$ tional Nature Reserve staff in strengthening the effectiveness of their existing outreach programme, and to improve understanding of factors associated with effective conservation awareness-raising across protected areas.

\section{Methods}

\section{Interview survey}

We conducted a household survey during May-June 2018 around Bawangling National Nature Reserve (Fig. 1). Thirty villages lie within $3 \mathrm{~km}$ of the Reserve boundary, in two counties (Baisha and Changjiang). We randomly selected 25 villages using satellite data from Google Earth (Google, 2018), ensuring that we sampled the majority of communities likely to interact with the Reserve and its biological resources. Target villages were relatively small, comprising $12-150$ households and $0.01-0.17 \mathrm{~km}^{2}$ in area. We recorded whether villages were exposed to visual gibbon awareness-raising materials (billboards, murals, posters) within a $500 \mathrm{~m}$ distance.

We aimed to conduct 10 interviews per village. We randomly selected respondents by traversing villages on foot, using criteria based on Turvey et al. (2017): villagers younger than 18 were not interviewed, only one respondent was interviewed per household to ensure independence of responses, and both male and female respondents were interviewed. We used a standard anonymous questionnaire for all interviews, comprising contrast, structured and open-ended questions, that took up to 45 minutes to complete (Supplementary Material 1). We explained that we were conducting interviews to research local wildlife, obtained verbal consent before all interviews, and informed respondents they could halt the interview at any time. All interviews were conducted by a female native Mandarin speaker (JQ) and recorded in writing in Chinese; most villagers spoke Mandarin, but some older people spoke only Li and Miao languages, for which translation assistance was provided by bilingual villagers.

During interviews we collected demographic data on respondents' literacy level, age, gender, ethnicity, residence time in their village, occupation, average household income, education level, and visits to local forest within the Reserve. We then asked whether respondents were aware of the Reserve and why it was established, and showed A4-sized colour photographs of 10 mammals, including the rhesus macaque Macaca mulatta, ring-tailed lemur Lemur catta 

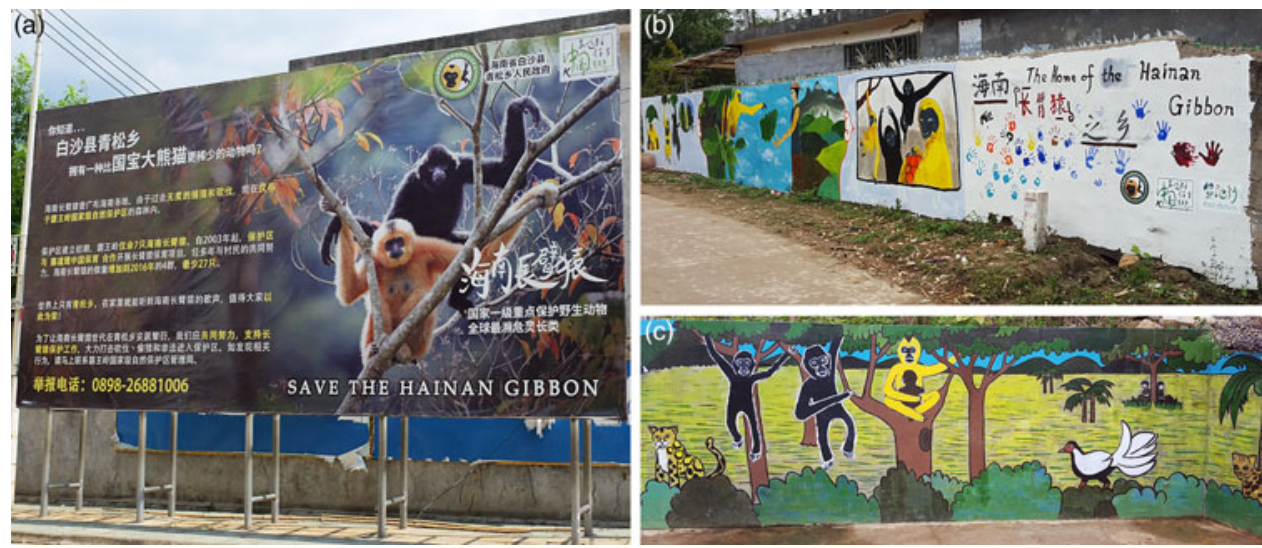

Plate 1 Conservation awareness-raising billboards and murals in villages adjacent to Bawangling National Nature Reserve (Fig. 1). (a) Billboard in Qingsongxiang, (b) mural in Zhizaixincun, and (c) mural in Miaocun. and Hainan gibbon, and asked about recognition of each species and if it occurred in the forest (Supplementary Material 1). Photographs were sourced from Arkive (2018) and were shown in the same order in all interviews. Use of multiple species aimed to obscure the potential importance of any single species within the survey, and therefore increase the likelihood of reporting potentially sensitive information (Turvey et al., 2017). Nine of these species are present (or occurred recently) within the Reserve (Kadoorie Farm \& Botanic Garden, 2001). The rhesus macaque, the other primate native to Hainan, was used as a control to assess effectiveness of gibbon awareness-raising, because awareness-raising activities have not included information about macaques. The ring-tailed lemur was used as a negative control to check response accuracy; however, 22 respondents thought it was a civet, so we retained data from these respondents because several civet species occur locally (Kadoorie Farm \& Botanic Garden, 2001). After showing each photograph, we asked respondents to describe the species' diet and any relevant conservation legislation. After showing the gibbon photograph, we also asked questions about the distribution, abundance, and threats for this species, and an open question about gibbon characteristics, to encourage respondents to provide additional knowledge, stories, and/or beliefs about gibbons (cf. White et al., 2005). If respondents did not recognize the gibbon photograph, we used standard Mandarin, Li or Miao names to prompt recall. We asked respondents about their source(s) of information for answers to questions about the Reserve, gibbons and macaques. Finally, we asked respondents about their access to news and social media, and preferences regarding different potential future awareness-raising methods. Additional data collected during interviews will be analysed elsewhere to investigate other conservation-relevant questions.

\section{Analysis}

We analysed data using $R$ 3.4.2 (R Development Core Team, 2017). We divided respondent education level and reported primary occupation into two categories for analysis, based on response proportions from interviews (education level: below middle school $=55.1 \%$, middle school and above $=$ $44.9 \%$; primary occupation: farmer $=85.5 \%$, non-farmer $=$ 14.5\%). We divided respondent awareness-raising exposure level into two categories: exposed and not exposed. Although all villages within $3 \mathrm{~km}$ of the Reserve have been visited by Reserve management office staff, and often also by other stakeholders, during previous outreach activities (Bawangling National Nature Reserve management office, pers. comm., 2018), no comprehensive or consistent data are available on the timing, frequency or content of these activities. However, five villages in Baisha County, at the opposite end of the Reserve from the management office in Bawangling Town, have gibbon-themed conservation billboards (large free-standing canvas structures displaying photographs and printed text) and/or murals (paintings made by hand on houses or walls) displayed within $500 \mathrm{~m}$ of the village: Miaocun (mural, billboard), Qingsongxiang (mural, billboard), Qingxincun (mural), Xinfengcun (mural), Zhizaixincun (mural) (Plate 1, Fig. 1). We interpreted these permanent displays as likely to provide greater local exposure to gibbon conservation-relevant information and classified respondents from these villages as exposed (21.3\%). Respondents from other villages were classified as not exposed (78.7\%).

We conducted exploratory tests to investigate robustness of sampling design. We assessed variation in demographic variables between villages using univariate generalized linear models (GLMs), using village as predictor variable, and Gaussian error structure (age) or binomial error structure (gender, education, occupation, frequency of visits to local forest, exposure to permanent displays) with logit link function. Because of limited ethnic variation ( $\mathrm{Li}, 91 \%$; Miao, 5\%; Han, 4\%), we excluded ethnicity as a predictor. Nearly all respondents (93.7\%) had always lived in the same village, had moved from a nearby village, or had lived in their current village for $>10$ years, so we also excluded residence time as a predictor. The two categorical variables of literacy and education level were positively correlated $\left(\chi^{2}\right.$ test, $\left.\mathrm{P}<0.001\right)$, so we only included education 


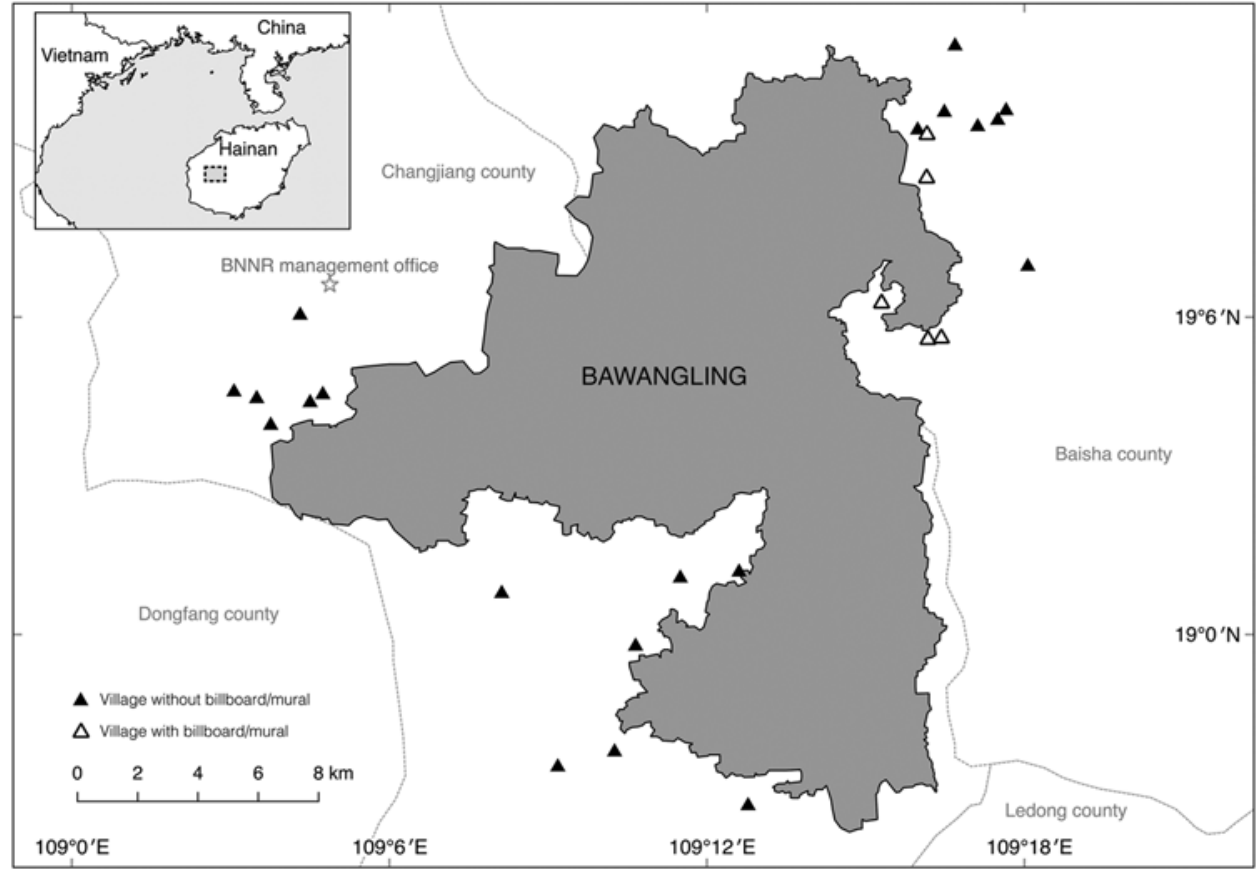

FIg. 1 Location of the 25 villages around Bawangling National Nature Reserve (BNNR) where interviews were conducted, and indicating those villages with gibbonthemed billboards and/or murals displayed within $500 \mathrm{~m}$ of the village, and location of Reserve management office. level as this predictor represents a wider category of knowledge acquisition than just reading ability.

Because of significant variation between villages in education level and frequency of forest visits (univariate GLM, $\mathrm{P}<0.05$ ), we investigated factors affecting respondent awareness using full additive mixed multivariate GLMs (binomial error structure with logit link function), with seven predictors included as fixed effects (age, gender, education, occupation, frequency of forest visits, exposure to permanent displays, distance of village from management office), and interview locality (village) as a random effect. Respondent awareness about the Reserve was investigated using two binary response variables: (1) awareness about existence of the Reserve; (2) awareness about the reason for Reserve establishment. Respondent awareness about gibbons was investigated using eight binary response variables: (1) ability to identify gibbon photograph; (2) awareness about existence of gibbons in Reserve; (3) knowledge about gibbon diet; (4) other knowledge about gibbons; (5) awareness about rarity of gibbons (scale of: extinct/miejue le, rare/hen shao, many/hen duo); (6) knowledge about gibbon population size; (7) knowledge about gibbon conservation status; (8) knowledge about threats to gibbons. We applied the same process to investigate four measures of respondent awareness about macaques: (1) ability to identify macaque photograph; (2) awareness about existence of macaques in Reserve; (3) knowledge about macaque diet; (4) knowledge about macaque conservation status. We applied step-wise model selection for each analysis, removing the insignificant predictor with the highest P-value at each step. We investigated differences in respondent awareness about gibbons and macaques using $\chi^{2}$ goodness-of-fit tests.

\section{Results}

We interviewed 212 respondents and completed 207 interviews (mean 8.28 interviews/village; mean age $41.4 \pm$ SD 13.7, range $18-80$; men, $62 \%$, women, $38 \%$ ). Most respondents were illiterate $(48.8 \%)$ or had limited literacy $(25.6 \%)$, and most had an annual household income of $<10$,000 yuan (c. GBP 1,100; 88.4\%). Most respondents watched television (79.2\%), had access to smartphones (61.4\%), and used the Chinese social media platform WeChat (58.5\%); access to other news and media outlets (radio, newspapers, computers, internet) was $<25 \%$. About one-third of respondents (34.3\%) reported visiting the forest inside the Reserve more than once per month. Levels of awareness for different questions are shown in Fig. 2. Significant predictors in final models are reported in Table 1.

\section{Information sources}

Respondents reported obtaining information about the Reserve, gibbons, and/or macaques from multiple sources: seeing or hearing these species, participating in or witnessing hunting, other villagers (family members, people in same or other villages), awareness-raising activities, and guesswork or assumption (Fig. 3).

Overall, 165 respondents credited awareness-raising sources for providing knowledge about local existence of gibbons, 48 for knowledge about gibbon population status, 83 for knowledge about conservation legislation, and 26 for knowledge about threats. Reported sources included: (1) education sessions organized within villages by management office (133 respondents; broadcasting information 


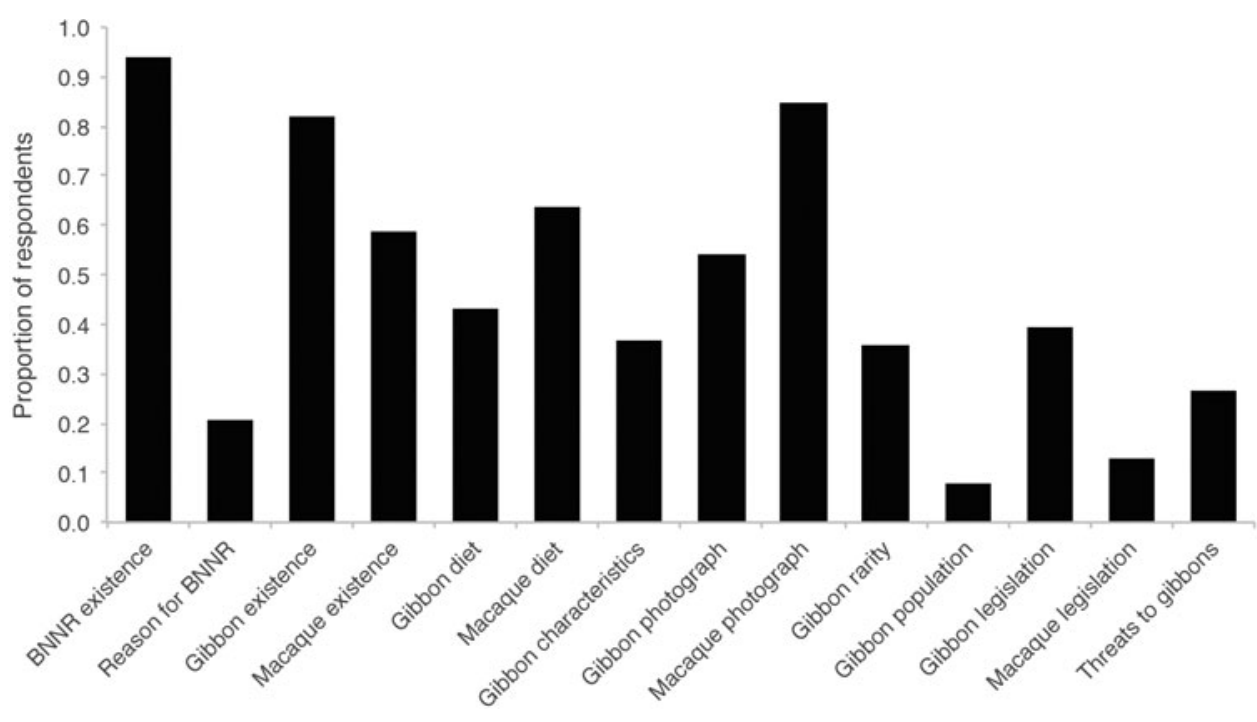

FIG. 2 Levels of local awareness, as proportion of respondents aware, about Bawangling National Nature Reserve (BNNR), gibbons and macaques. using speakers on mobile vehicle, displaying photographs, showing videos, face-to-face communication); (2) billboards (68); (3) murals (1); (4) other visual media (29; television, internet, newspapers, brochures, themed calendars); (5) directly from teachers at local schools (17); (6) children who brought information back from school (7); (7) local authorities (14; local government, forest police); (8) NGOs (17); (9) visiting foreign researchers (16); (10) visiting Chinese researchers, students, photographers and/or tourists (20) (Fig. 4).

\section{Knowledge of Reserve and primates}

Overall, almost all respondents (94.2\%) had heard of the Reserve, but only $49.8 \%$ said they knew why it was established, and $20.8 \%$ knew it had been established for gibbon conservation. Gender was the only significant predictor of awareness of the Reserve, with male respondents more likely to be aware $(\mathrm{P}=0.043)$, whereas education level $(\mathrm{P}=0.002)$ and increasing distance from management office $(\mathrm{P}=0.024)$ were significant predictors of increased awareness about why the Reserve was established.

Over half $(54.1 \%)$ of respondents could identify gibbons, and a further $28.0 \%$ were initially unable to, but recognized the photo after prompting with Mandarin or local names. Significantly more respondents were able to identify macaques $(85.0 \%)$ compared to gibbons $(54.1 \%)\left(\mathrm{n}=207 ; \chi^{2}=80.208\right.$, $\mathrm{df}=1, \mathrm{P}<0.001)$. Exposure to billboards and/or murals $(\mathrm{P}=0.010)$ and male gender $(\mathrm{P}=0.004)$ positively predicted ability to identify gibbons. Conversely, male gender $(\mathrm{P}=0.006)$, farming occupation $(\mathrm{P}=0.029)$ and education level $(\mathrm{P}=0.033)$ positively predicted ability to identify macaques.

Overall, $82.1 \%$ of respondents knew gibbons existed in the Reserve. Respondents reported knowing about gibbon presence mainly from awareness-raising activities (44.6\%), other villagers (36.1\%), or experience of seeing or hearing gibbons (18.1\%). Amongst different awareness-raising activities, the most frequently reported information sources were village education sessions (40.6\%) and billboards (26.7\%). Male gender $(\mathrm{P}=0.010)$ was the only significant predictor of awareness of gibbon presence, although exposure to billboards and/or murals was nearly significant $(\mathrm{P}=0.096)$. Significantly more respondents were aware of local existence of gibbons compared to macaques $(58.9 \%)(n=207$; $\left.\chi^{2}=74.595, \mathrm{df}=1, \mathrm{P}<0.001\right)$. Awareness of macaque presence was predicted by increasing age $(\mathrm{P}=0.018)$, farming occupation $(\mathrm{P}=0.049)$ and education level $(\mathrm{P}=0.004)$.

Over half of respondents (54.6\%) reported accurate knowledge about gibbon diet (e.g. fruit), but significantly more respondents knew about macaque diet $(63.8 \%)(\mathrm{n}=$ 207; $\left.\chi^{2}=7.957, \mathrm{df}=1, \mathrm{P}=0.005\right)$. Exposure to billboards and/or murals $(\mathrm{P}=0.010)$, increasing age $(\mathrm{P}=0.012)$, education level $(\mathrm{P}<0.001)$, and decreasing distance from management office $(\mathrm{P}=0.046)$ were significant predictors of knowledge of gibbon diet. Conversely, male gender $(\mathrm{P}<0.001)$ and increasing age $(\mathrm{P}=0.018)$ predicted knowledge of macaque diet. Overall, $36.7 \%$ of respondents provided additional information about gibbons, including ecological (17.4\%) and morphological characteristics (12.6\%), protection status $(8.7 \%)$, utilization methods (5.8\%), or cultural beliefs (5.3\%). This included methods for hunting and preparing gibbons, use of gibbon arm bones to make chopsticks, and use of gibbon gallbladder (Supplementary Table 2). Exposure to billboards and/or murals $(\mathrm{P}=0.012)$ and increasing age $(\mathrm{P}<0.001)$ were significant predictors of knowledge, with male gender also nearly significant $(\mathrm{P}=0.068)$.

\section{Knowledge of primate status, protection and threats}

Only $35.7 \%$ of respondents thought gibbons were rare, and only $7.7 \%$ knew there were $20-30$ gibbons within the 
TABLE 1 Final models investigating factors that affected local awareness about Bawangling National Nature Reserve, the Hainan gibbon Nomascus hainanus, and the rhesus macaque Macaca mulatta.

\begin{tabular}{|c|c|c|c|}
\hline Predictor & Estimate $\pm \mathrm{SE}$ & $z$ & $\mathrm{P}$ \\
\hline \multicolumn{4}{|c|}{ Awareness about existence of Reserve } \\
\hline Intercept & $2.169 \pm 0.373$ & 5.812 & $<0.00$ \\
\hline Gender (male) & $1.273 \pm 0.630$ & 2.020 & 0.04 \\
\hline \multicolumn{4}{|c|}{ Awareness about reason for establishment of Reserve } \\
\hline Intercept & $-2.671 \pm 0.449$ & -5.947 & $<0.00$ \\
\hline $\begin{array}{l}\text { Education (middle school \& } \\
\text { above) }\end{array}$ & $1.114 \pm 0.367$ & 3.031 & 0.00 \\
\hline $\begin{array}{l}\text { Distance to management } \\
\text { office }\end{array}$ & $0.016 \pm 0.007$ & 2.253 & 0.02 \\
\hline
\end{tabular}

\section{Identify gibbon photograph}

Intercept

Billboard/mural (yes)

$-0.595 \pm 0.261-2.278$

Gender (male)

$1.073 \pm 0.414 \quad 2.591$

$0.891 \pm 0.307 \quad 2.898$

0.023

0.010

0.004

Awareness of gibbons in Reserve

Intercept

$0.840 \pm 0.268$

Billboard/mural (yes)

Gender (male)

$0.941 \pm 0.566$

$0.962 \pm 0.372$

3.130

1.663

2.582

\section{Knowledge of gibbon diet}

\section{Intercept}

Billboard/mural (yes)

Age

$$
-1.756 \pm 0.633 \quad-2.775
$$

$1.206 \pm 0.471 \quad 2.559$

$0.030 \pm 0.012 \quad 2.513$

Education (middle school \&

$1.273 \pm 0.335$

2.513
3.798 above)

Distance to management office

$-0.014 \pm 0.007-1.992$

Other gibbon knowledge
Intercept
Billboard/mural (yes)
Age
Gender (male)

Awareness of gibbon rarity

$\begin{array}{lrrr}\text { Intercept } & -0.056 \pm 0.584 & -0.096 & 0.923 \\ \text { Age } & -0.023 \pm 0.013 & -1.808 & 0.071 \\ \begin{array}{l}\text { Education (middle school \& } \\ \quad \text { above) }\end{array} & 0.775 \pm 0.321 & 2.413 & 0.016 \\ & & & \end{array}$

Knowledge of gibbon population size

$\begin{array}{lrrr}\text { Intercept } & -7.034 \pm 1.489 & -4.723 & <0.001 \\ \begin{array}{l}\text { Education (middle school \& } \\ \quad 1.760 \pm 0.677\end{array} & 2.599 & 0.009 \\ \begin{array}{l}\text { above) } \\ \begin{array}{l}\text { Distance to management } \\ \quad \text { office }\end{array}\end{array} & 0.060 \pm 0.020 & 2.991 & 0.003 \\ & & & \end{array}$

$\begin{array}{lrrr}\text { Knowledge of gibbon conservation legislation } & & \\ \text { Intercept } & -2.356 \pm 0.418 & -5.631 & <0.001 \\ \text { Billboard/mural (yes) } & 2.253 \pm 0.548 & 4.116 & <0.001 \\ \text { Gender (male) } & 1.356 \pm 0.383 & 3.543 & <0.001 \\ \text { Education (middle school \& } & 1.086 \pm 0.362 & 2.998 & 0.003\end{array}$
above)

$$
\begin{array}{rrr}
-3.109 \pm 0.632 & -4.923 & <0.001 \\
1.126 \pm 0.447 & 2.522 & 0.012 \\
0.044 \pm 0.012 & 3.624 & <0.001 \\
0.629 \pm 0.345 & 1.824 & 0.068
\end{array}
$$

0.071

\section{6} awareness-raising activities (77.8\%). Amongst different awareness-raising activities, billboards $(36.8 \%)$ and village education sessions $(31.6 \%)$ were the primary knowledge sources.

Overall, 39.6\% of respondents knew gibbons were National Level I protected species; significantly fewer knew macaques were National Level II protected species (13.0\%) $(\mathrm{n}=207$; $\chi^{2}=62.674, \mathrm{df}=1, \mathrm{P}<0.001$ ). Knowledge about both gibbon and macaque conservation status was predicted by male gender (gibbon, $\mathrm{P}<0.001$; macaque, $\mathrm{P}=0.021$ ) and education level (gibbon, $\mathrm{P}=0.003$; macaque, $\mathrm{P}=0.001$ ). Gibbon knowledge was also predicted by exposure to billboards and/or murals $(\mathrm{P}<0.001)$, and this predictor was nearly significant for macaque knowledge $(\mathrm{P}=0.056)$. Respondents who knew about conservation status obtained their information from awareness-raising activities (64.6\%), other villagers (26.0\%), or guesswork or assumption (9.4\%). Primary contributors to

\footnotetext{
Awareness of threats to gibbons

Intercept $\quad-1.812 \pm 0.270-6.722<0.001$

Education (middle school \& $\quad 1.487 \pm 0.342 \quad 4.350<0.001$ above)
}

Table 1 (Cont.)

\begin{tabular}{lrrr}
\hline Predictor & Estimate \pm SE & \multicolumn{2}{l}{ 年 } \\
\hline Identify macaque photograph & & & \\
Intercept & $-0.136 \pm 0.526$ & -0.258 & 0.797 \\
Gender (male) & $1.150 \pm 0.420$ & 2.741 & 0.006 \\
Occupation (farmer) & $1.126 \pm 0.517$ & 2.178 & 0.029 \\
Education (middle school \& & $1.008 \pm 0.473$ & 2.131 & 0.033 \\
$\quad$ & & &
\end{tabular}

Awareness of macaques in Reserve

$\begin{array}{lrrr}\text { Intercept } & -2.015 \pm 0.696 & -2.894 & 0.004 \\ \text { Age } & 0.030 \pm 0.013 & 2.358 & 0.018\end{array}$

$\begin{array}{llll}\text { Occupation (farmer) } & 0.885 \pm 0.450 & 1.968 & 0.049\end{array}$

Education (middle school \& $\quad 0.980 \pm 0.342 \quad 2.868 \quad 0.004$

Knowledge of macaque diet

$\begin{array}{llll}\text { Age } & 0.028 \pm 0.012 & 2.370 & 0.018\end{array}$

Gender (male) $\quad 1.221 \pm 0.320 \quad 3.818<0.001$

Reserve. Education level was the only predictor of awareness of rarity $(\mathrm{P}=0.016)$, with increasing age also almost signifidistance from management office $(\mathrm{P}=0.003)$ predicted accurate knowledge of gibbon population size. Respondents reported knowing about gibbon population size mainly activities $(34.6 \%)$ or other villagers $(24.3 \%)$. However, respondents who used guesswork or assumption provided a correct population estimate, with correct estimates mainly provided by respondents whose information came from 


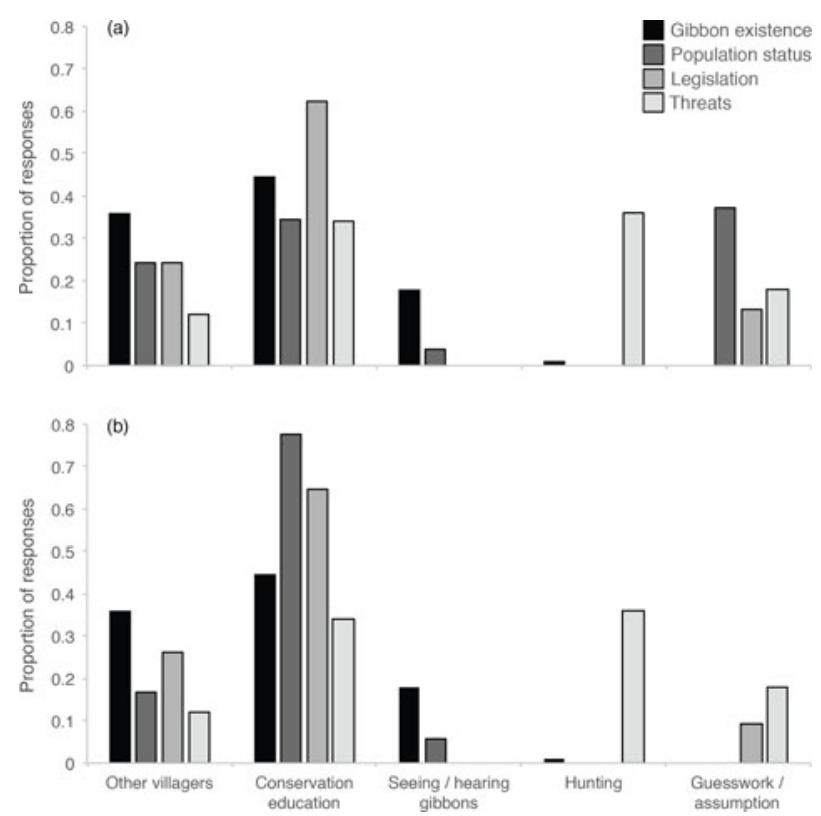

FIG. 3 Reported sources of respondent knowledge, as proportion of respondents, about local gibbon existence, population status, conservation legislation, and threats: (a) all responses, and (b) responses from respondents who provided correct answers to relevant questions.

local awareness amongst all awareness-raising activities were village education sessions (50.8\%) and billboards (19.0\%).

Almost three-quarters (73.9\%) of respondents were unaware of factors that could threaten gibbons. Perceived threats included hunting (13.5\%), human-related threats (no details; $4.3 \%$ ), habitat destruction $(3.4 \%)$, or other factors (snakes, illness, small population, limited habitat, poor Reserve management; 3.9\%), and 1.4\% thought there were no threats to gibbons. Hunting was also mentioned 44 times by respondents when discussing other species in the questionnaire. Education level was the only predictor of awareness of threats to gibbons $(\mathrm{P}<0.001)$, with threat awareness mainly derived from experience or observation of hunting (36.0\%) and awareness-raising activities (34.0\%). Amongst different awareness-raising activities, village education sessions (42.3\%) and NGOs (15.4\%) were the primary sources of knowledge.

\section{Future awareness-raising}

Overall, $75.4 \%$ of respondents reported they would be happy to receive more information about conservation in Hainan. When asked their preferences about 11 possible awarenessraising options, respondents showed strongest preference for games or lectures in schools (like very much, 64.7\%; do not like/dislike, $4.3 \%$ ), with video-watching, calendars or local workshops strongly liked by $>50 \%$ of respondents and not liked/disliked by $12-13 \%$. Photo exhibitions and billboards were strongly liked by $<50 \%$ of respondents; posters, games

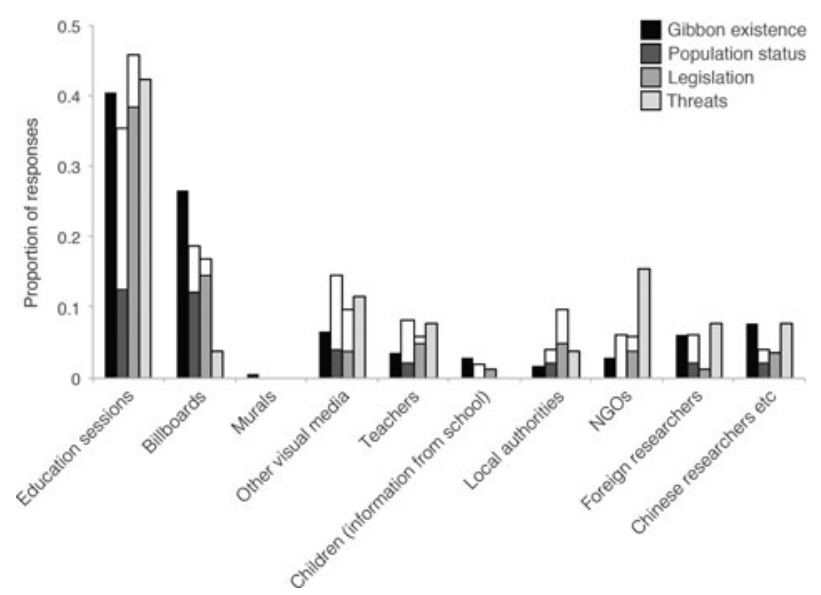

FIG. 4 Reported awareness-raising information sources about local gibbon existence, population status, conservation legislation, and threats, as proportions of total number of respondents who reported awareness-raising as a source of knowledge. Shaded and unshaded portions of stacked plots indicate proportions of respondents who gave correct and incorrect answers to questions based on the information source, respectively.

or lectures in villages, brochures, and murals were strongly liked by $<40 \%$; and audio announcements were strongly liked by only $26.1 \%$ and not liked/disliked by $41.1 \%$ (Supplementary Fig. 1). Respondents did not report strong preferences for the time of year they preferred to receive awareness-raising (all months, $n=5-19$ suggestions), but 57 respondents suggested June was a bad time (all other months, 4-20 suggestions).

\section{Discussion}

This study constitutes the first systematic assessment of awareness-raising efforts conducted to support Hainan gibbon conservation, and one of the first assessments of effectiveness of conservation education in China. Our analysis of interview data from most communities of local forest users situated close to Bawangling National Nature Reserve provides a baseline for assessing multiple indices of conservation awareness. Even without longitudinal time-series data to compare post-campaign responses against a precampaign baseline (cf. Howe et al., 2012), our comparison of variation in knowledge and attitudes, together with specific enquiries about knowledge sources, suggest positive effects of past awareness-raising at increasing local conservation knowledge about one of the world's rarest mammals. Awareness-raising initiatives can assist protected areas in improving their community-based conservation programmes (Trewhella et al., 2005; Liu et al., 2010), and our study identifies remaining conservation knowledge gaps that can be targeted more effectively in the future. 
Our analyses demonstrate that most indices of conservationrelevant knowledge about the Reserve, gibbons, and other locally-occurring species (e.g. macaques) are positively correlated with socio-demographic parameters that are known predictors of increased environmental knowledge acquisition in other systems, notably respondent age, education level, gender, and rural rather than urban livelihoods (Nyhus et al., 2003; Turvey et al., 2010, 2017). For example, male gender is associated with increased environmental knowledge in other communities adjacent to Chinese protected areas, although specific causes of this pattern are unclear (Allendorf \& Yang, 2017); it might reflect genderdifferentiated activities inside protected areas (e.g. hunting), or differing interactions with Reserve staff during villagebased education sessions.

However, models including these parameters indicate that numerous indices of conservation-relevant knowledge in communities around Bawangling are also positively correlated with exposure to awareness-raising materials, with likelihood of accurate responses to most of our questions about gibbons (ability to identify gibbons; local presence of gibbons; diet; other knowledge; gibbon conservation status) increased with proximity to gibbon-themed billboards and murals. Accurate responses to further gibbon-related questions (why the Reserve was established; gibbon population size) were associated with increased distance from the management office, which we interpret as probably also representing closer proximity to gibbon-themed billboards and murals, which are located at the north-east of the Reserve in Baisha County (Fig. 1). Further support for effectiveness of gibbon-focused outreach activities is demonstrated by comparison of respondent knowledge about primates present in the Reserve, with more respondents aware of local existence and conservation status of gibbons compared to macaques, and with exposure to billboards or murals statistically associated with increased likelihood of identifying and knowing about local existence of gibbons but not macaques. A substantial proportion of respondents also specifically reported they knew about local existence, population size (and especially correct estimation of population size), conservation status, and threats to gibbons from awareness-raising initiatives.

More than $82 \%$ of respondents living near Bawangling were aware that gibbons live within the Reserve, representing greater awareness compared to the previous community survey in 2015 (Turvey et al., 2017). This difference might represent more accurate assessment of awareness associated with greater sample size and coverage (207 respondents in 25 villages in this study, versus 107 respondents in 10 villages in 2015), or positive changes associated with recent awareness-raising, although we are unable to test between these hypotheses. However, despite widespread awareness of gibbons, only $54.1 \%$ of respondents could identify gibbons without prompting, far fewer than could identify macaques despite the absence of awareness-raising about this less threatened species, and markedly fewer than could identify gibbons in 2015 ( $74 \%$; Turvey et al., 2017). Significantly more respondents also knew about macaque diet compared to gibbon diet, a question that aimed to gauge general familiarity with species' ecology and behaviour; less than $40 \%$ of respondents understood the gibbon's top-level protected status; and few respondents knew gibbons were rare, that the Reserve was established for gibbon conservation, or could name factors that might threaten gibbons. Knowledge of potential threats was most frequently attributed to personal experience or observation of hunting rather than conservation awareness-raising. Although educational activities have improved local awareness about gibbons and their conservation requirements in relative terms, there is therefore still considerable need for further improvement of awareness in absolute terms, and increasing knowledge among adults in communities around Bawangling will probably require more intensive activities as opposed to relying on passive knowledge transfer.

Although systematic baseline data on levels, frequency, or content of past awareness-raising activities are limited, numerous activities organized by local, regional and international stakeholders were recalled by respondents. Miaocun and nearby communities in Baisha County have received periodic public engagement and assessment of development needs that aimed to increase local support and involvement in conservation (Fauna \& Flora International China Programme, 2005; Fellowes et al., 2008); the observed correlation between local visual displays and increased awareness might therefore be associated with broader outreach activities in Baisha County rather than direct cause and effect. However, education sessions organized by Reserve staff and billboards were repeatedly identified as by far the most important direct sources of conservation-relevant information, thus complementing the statistical association between billboards and increased awareness in our models, and indicating that information on billboards has directly enhanced local conservation knowledge. Our findings appear to represent the first evidence that billboards can be an effective medium to raise awareness about primate conservation (Junker et al., 2019). The combined predictor of 'billboards and/or murals' was significant in our models, and presence of permanent public art displays might make gibbons and other species more salient in nearby communities and aid in remembering and recall of conservation-relevant information (cf. Song, 2008; Song \& Gammel, 2011). However, gibbon murals around Bawangling contain little or no conservation-relevant text (Plate 1), and only one respondent reported having learnt new information about gibbons or conservation from murals, suggesting this statistical pattern may have been driven largely by the effectiveness of billboards (Fig. 4).

Although respondents recalled other awareness-raising approaches conducted by different stakeholders, these 
apparently had little effect on shaping local conservation awareness according to reported sources of knowledge. This discrepancy in effectiveness might reflect variation in the quality of past activities; alternately, it might simply indicate that other activities have been conducted less frequently, and/or other stakeholders have been able to maintain a less regular or continuous presence at Bawangling compared to Reserve staff. We cannot assess these alternatives further without systematic data on frequency, content and delivery of past activities. However, our results provide little direct evidence for the effectiveness of outreach activities aimed at schoolchildren (e.g. presentations, field visits, entertainment education), even though these have been periodically conducted in local schools from the 200os onwards (Fauna \& Flora International China Programme, 2005; Fellowes et al., 2008), indicating that younger adults within our respondent sample should have been exposed to such activities as children. These activities are a regular component of communication, education and public awareness and other conservation campaigns (van der Ploeg et al., 2011), and have been effective in other social-ecological systems in improving knowledge of threatened biodiversity amongst children (Rakotomamonjy et al., 2015; Freund et al., 2019) and parents (Damerell et al., 2013). Their apparent ineffectiveness at Bawangling might reflect a lack of local intergenerational knowledge transfer about biodiversity, as documented in other social-ecological systems in China (Turvey et al., 2010), or limited opportunities for direct or indirect exposure to school learning in rural Hainan, where many respondents were illiterate or had limited literacy. The strong positive correlation between many indices of conservation-relevant knowledge and respondent age also provides no evidence for knowledge uptake at school by younger respondents (i.e. recent schoolleavers). Although the similar positive correlation observed with education level may represent indirect evidence of effective awareness-raising targeted at schools, overall these results emphasize the importance of increasing adult awareness to support Hainan gibbon conservation.

Our study provides a new baseline to inform future community-based conservation activities for Hainan gibbons and other threatened species. Model outputs identify important topics that remain poorly understood in local communities (e.g. why the Reserve was established; gibbon population status, conservation importance, and threats) and in socio-demographic groups possessing less conservation knowledge (women, younger people, non-farmers), which should be targeted in future outreach activities. Future conservation education should be customized to target these knowledge gaps and optimize awareness-raising outcomes (Kanagavel et al., 2013), with appropriate adaptation to local cultural perspectives and alignment with Indigenous ecological knowledge and values (Yuan et al., 2011). Such initiatives should also use locally preferred methods (e.g. avoiding audio broadcasts, which respondents generally disliked), and find innovative ways to package information together to deliver a complete conservation story for more comprehensive local understanding. Our data on previously successful approaches suggest that construction of additional conservation-themed billboards could constitute a relatively cost-effective strategy to increase local awareness about gibbons and other biodiversity, in combination with ongoing village education sessions. Most respondents reported they were happy to receive further conservation information, and their stated preferences for particular educational approaches should be incorporated into future campaigns to improve information-uptake. Such approaches could also use media outlets and social media platforms (e.g. television, WeChat) that are accessed by the majority of respondents.

More widely, the effectiveness of other activities conducted to support Hainan gibbon conservation should also be critically evaluated (e.g. tree-planting to restore forest connectivity; Fellowes et al., 2008). General education levels need to be improved in this low-income region (Fauna \& Flora International China Programme, 2005; Turvey et al., 2015), and awareness-raising methods requiring reading abilities might not reach the large number of local people with limited literacy. Our study focused on determining levels of conservation-relevant knowledge, but it is also important to assess patterns and drivers of local behaviours and attitudes (e.g. empathy, intrinsic value) associated with gibbons and conservation, as such factors will also influence management outcomes. Ultimately, it is essential to understand the relationship between knowledge, attitudes and behaviours, and interact with local communities in ways that will inspire beneficial attitudinal and behaviour change and result in positive conservation outcomes at Bawangling (Jacobson, 2010; Kling \& Hopkins, 2015). Through such an approach, carefully designed and organized awareness-raising initiatives could hopefully support community-based conservation programmes to prevent extinctions of threatened species in China and elsewhere.

Acknowledgements We thank the Indigenous communities of Hainan for sharing their knowledge, Bawangling National Nature Reserve management office, the Provincial Forestry Department of Hainan, Xuming Qi and Sarah Papworth for logistical support and advice, and the Arcus Foundation and Imperial College London for financial support.

Author contributions Study design: JQ, STT, MM, HM; fieldwork: JQ, HM; data analysis: JQ; writing: JQ, STT.

\section{Conflicts of interest None.}

Ethical standards This study abided by the Oryx guidelines on ethical standards, and adhered to the code of ethics developed and endorsed by the British Sociological Foundation. Research was approved by the Hainan Provincial Forestry Department and Bawangling National Nature Reserve management office. The Ethics 
Committees of Imperial College London and the Zoological Society of London approved the project design.

\section{References}

Allendorf, T.D. \& Yang, J.M. (2017) The role of gender in local residents' relationships with Gaoligongshan Nature Reserve, Yunnan, China. Environment, Development and Sustainability, 19, 185-198.

Arkive (2018) arkive.org [accessed 30 April 2018].

Bajracharya, S.B., Furley, P.A. \& Newton, A.C. (2005)

Effectiveness of community involvement in delivering conservation benefits to the Annapurna Conservation Area, Nepal.

Environmental Conservation, 32, 239-247.

Berkes, F., Colding, J. \& Folke, C. (2000) Rediscovery of traditional ecological knowledge as adaptive management. Ecological Applications, 10, 1251-1262.

Booth, J.E., Gaston, K.J. \& Armsworth, P.R. (2009) Public understanding of protected area designation. Biological Conservation, 142, 3196-3200.

Chan, B.P.L., Fellowes, J.R., Geissmann, T. \& Zhang, J. (2005) Hainan Gibbon Status Survey and Conservation Action Plan. Technical Report 3, Kadoorie Farm \& Botanic Garden, Hong Kong.

Damerell, P., Howe, C. \& Milner-Gulland, E.J. (2013) Child-orientated environmental education influences adult knowledge and household behaviour. Environmental Research Letters, 8, 015016.

DenG, H., Zhang, M. \& Zhou, J. (2017) Recovery of the Critically Endangered Hainan gibbon Nomascus hainanus. Oryx, 51, 161-165.

Dzerefos, C.M. \& Witkowski, E.T.F. (2001) Density and potential utilisation of medicinal grassland plants from Abe Bailey Nature Reserve, South Africa. Biodiversity and Conservation, 10, 1875-1896.

Fauna \& Flora International China Programme (2005) Action Plan for Implementing Co-Management in the Bawangling Nature Reserve and Adjacent Communities in Qingsong Township. Fauna \& Flora International China Programme, Beijing, China.

Fellowes, J.R., Chan, B.P.L., Zhou, J., Chen, S., Yang, S. \& NG, S.C. (2008) Current status of the Hainan gibbon (Nomascus hainanus): progress of population monitoring and other priority actions. Asian Primates Journal, 1, 2-9.

Fernández-Llamazares, Á. \& Cabeza, M. (2018) Rediscovering the potential of indigenous storytelling for conservation practice. Conservation Letters, 11, e12398.

Ferraro, P.J. \& Pattanayak, S.K. (2006) Money for nothing? A call for empirical evaluation of biodiversity conservation investments. PLOS Biology, 4, e105.

Freund, C.A., Achmad, M., Kanisius, P., Naruri, R., Tang, E. \& KNotT, C.D. (2019) Conserving orangutans one classroom at a time: evaluating the effectiveness of a wildlife education program for school-aged children in Indonesia. Animal Conservation, 23, 18-27.

Google (2018) Google Earth Pro v.7.2. google.com/earth/download/ gep/agree.html [accessed 30 April 2018].

Howe, C., Obgenova, O. \& Milner-Gulland, E.J. (2012) Evaluating the effectiveness of a public awareness campaign as a conservation intervention: the saiga antelope Saiga tatarica in Kalmykia, Russia. Oryx, 46, 269-277.

Igota, H. \& SuZuki, M. (2008) Community-based wildlife management: a case study of sika deer in Japan. Human Dimensions of Wildlife, 13, 416-428.

JACOBSON, S.K. (2010) Effective primate conservation education: gaps and opportunities. American Journal of Primatology, 72, 414-419.

Junker, J., Kühl, H.S., Orth, L., Smith, R.K., Petrovan, S.O. \& Sutherland, W.J. (2019) Primate conservation. In What Works in Conservation 2019 (eds W.J. Sutherland, L.V. Dicks, N. Ockendon,
S.O. Petrovan \& R.K. Smith), pp. 439-491. Open Book Publishers, Cambridge, UK.

Kadoorie Farm and Botanic Garden (2001) Report of Rapid Biodiversity Assessments at Bawangling National Nature Reserve and Wangxia Limestone Forest, Western Hainan, 3 to 8 April 1998. South China Forest Biodiversity Survey Report Series 2, Kadoorie Farm and Botanic Garden, Hong Kong.

Kanagavel, A., Raghavan, R. \& Veríssimo, D. (2013) Beyond the "general public": implications of audience characteristics for promoting species conservation in the Western Ghats Hotspot, India. Ambio, 43, 138-148.

KLING, K.J. \& Hopkins, M.E. (2015) Are we making the grade? Practices and reported efficacy measures of primate conservation education programs. American Journal of Primatology, 77, 434-448.

Larson, L.R., Conway, A.L., Krafte, K.E., Hernandez, S.M. \& CARroll, J.P. (2016) Community-based conservation as a potential source of conflict around a protected area in Sierra Leone. Environmental Conservation, 43, 242-252.

Liv, J., Ouyang, Z. \& Miao, H. (2010) Environmental attitudes of stakeholders and their perceptions regarding protected area-community conflicts: a case study in China. Journal of Environmental Management, 91, 2254-2262.

Madden, F. (2004) Creating coexistence between humans and wildlife: global perspectives on local efforts to address humanwildlife conflict. Human Dimensions of Wildlife, 9, 247-257.

Monroe, M.C. (2003) Two avenues for encouraging conservation behaviors. Human Ecology Review, 10, 113-125.

Nyhus, P.J., Sumianto \& Tilson, R. (2003) Wildlife knowledge among migrants in southern Sumatra, Indonesia: implications for conservation. Environmental Conservation, 30, 192-199.

Ormsiy, A. \& Kaplin, B.A. (2005) A framework for understanding community resident perceptions of Masoala National Park, Madagascar. Environmental Conservation, 32, 156-164.

R Development Core Team (2017) R: A Language and Environment for Statistical Computing. R Foundation for Statistical Computing, Vienna, Austria.

Rakotomamonjy, S.N., Jones, J.P.G., RazafimanahaKa, J.H., Ramamonjisoa, B. \& Williams, S.J. (2015) The effects of environmental education on children's and parents' knowledge and attitudes towards lemurs in rural Madagascar. Animal Conservation, $18,157-166$

Sodhi, N.S., Posa, M.R.C., Lee, T.M., Bickford, D., Koh, L.P. \& Brook, B.W. (2010) The state and conservation of southeast Asian biodiversity. Trends in Ecology and Evolution, 19, 317-328.

SoNG, Y.I.K. (2008) Exploring connections between environmental education and ecological public art. Childhood Education, 85, 13-19.

SonG, Y.I.K. \& GAMMEL, J.A. (2011) Ecological mural as community reconnection. International Journal of Art \& Design Education, $30,266-278$.

Sutherland, W.J., Pullin, A.S., Dolman, P.M. \& Knight, T.M. (2004) The need for evidence-based conservation. Trends in Ecology and Evolution, 19, 305-308.

Trewhella, W.J., Rodriguez-Clark, K.M., Corp, N., Entwistle, A., Garrett, S.R.T., Granek, E. et al. (2005) Environmental education as a component of multidisciplinary conservation programs: lessons from conservation initiatives for Critically Endangered fruit bats in the Western Indian Ocean.

Conservation Biology, 19, 75-85.

Turvey, S.T., Barrett, L.A., Hao, Y., Zhang, L., Zhang, X., WANG, X. et al. (2010) Rapidly shifting baselines in Yangtze fishing communities and local memory of extinct species. Conservation Biology, 24, 778-787.

Turvey, S.T., Bryant, J.V., Duncan, C., Wong, M.H.G., Guan, Z., FEI, H. et al. (2017) How many remnant gibbon populations are left 
on Hainan? Testing the use of local ecological knowledge to detect cryptic threatened primates. American Journal of Primatology, 79, e22593.

Turvey, S.T., Traylor-Holzer, K., Wong, M.H.G., Bryant, J.V., ZENG, X., HonG, X. et al. (eds) (2015) International Conservation Planning Workshop for the Hainan Gibbon: Final Report. Zoological Society of London, London, UK \& IUCN SSC Conservation Breeding Specialist Group, Apple Valley, USA.

UNEP-WCMC \& IUCN (2016) Protected Planet Report 2016. UNEP-WCMC and IUCN, Cambridge, UK and Gland, Switzerland.

van der Ploeg, J., Caullan-Cureg, M., van Weerd, M. \& De Groот, W.T. (2011) Assessing the effectiveness of environmental education: mobilizing public support for Philippine crocodile conservation. Conservation Letters, 4, 313-323.

White, P.C.L., Jennings, N.V., Renwick, A.R. \& Barker, N.H.L. (2005) Questionnaires in ecology: a review of past use and recommendations for best practice. Journal of Applied Ecology, 42, 421-430.

Wild, C., Morgan, B.J. \& Dixson, A. (2005) Conservation of drill populations in Bakossiland, Cameroon: historical trends and current status. International Journal of Primatology, 26, 759-773.

Yuan, N., Xue, D. \& Peng, Y. (2011) The roles of traditional knowledge in biodiversity conservation for Li ethnic people in Hainan Island of China. Journal of Minzu University of China (Natural Sciences Edition), 20, 30-33. 